\title{
Variables associated with interprofessional collaboration: a comparison between primary healthcare and specialized mental health teams
}

Nicolas Ndibu Muntu Keba Kebe ${ }^{1}$, François Chiocchio ${ }^{2}$, Jean-Marie Bamvita ${ }^{3}$ and Marie-Josée Fleury ${ }^{4^{*}}$ (D)

\begin{abstract}
Background: This study has two aims: first, to identify variables associated with interprofessional collaboration (IPC) among a total of 315 Quebec mental health $(\mathrm{MH})$ professionals working in $\mathrm{MH}$ primary care teams $(\mathrm{PCTs}, N=101)$ or in specialized service teams (SSTs, $N=214$ ); and second, to compare IPC associated variables in MH-PCTs vs MHSSTS.

Methods: A large number of variables acknowledged as strongly related to IPC in the literature were tested. Multivariate regression models were performed on MH-PCTs and MH-SSTs respectively.

Results: Results showed that knowledge integration, team climate and multifocal identification were independently and positively associated with IPC in both MH-PCTs and MH-SSTs. By contrast, knowledge sharing was positively associated with IPC in MH-PCTs only, and organizational support positively associated with IPC in MH-SSTs. Finally, one variable (age) was significantly and negatively associated with IPC in SSTs.

Conclusions: Improving IPC and making MH teams more successful require the development and implementation of differentiated professional skills in MH-PCTs and MH-SSTs by care managers depending upon the level of care required (primary or specialized). Training is also needed for the promotion of interdisciplinary values and improvement of interprofessional knowledge regarding IPC.
\end{abstract}

Keywords: Interprofessional collaboration, Mental health teams, Variables associated, Primary care teams, Specialized services teams

\section{Background}

Interprofessional collaboration (IPC) is defined as a process by which professionals from multiple disciplines share roles and tasks in order to respond in a coherent and integrated way to the needs of patients, their loved ones and the community [1,2]. IPC has benefits for patients, health professionals, healthcare organizations and health systems [3, 4]. Studies have shown that good IPC reduces healthcare costs and expenditures, enhances quality of care and increases job satisfaction, improving

\footnotetext{
* Correspondence: flemar@douglas.mcgill.ca

${ }^{4}$ Department of Psychiatry, McGill University; Douglas Hospital Research Centre, Douglas Mental Health University Institute, 6875 LaSalle Boulevard, Montreal, Quebec H4H 1R3, Canada

Full list of author information is available at the end of the article
}

staff retention and patient outcomes [5, 6]. IPC responds to the shortage of financial, human, and technical resources by providing solutions that increase the effectiveness and efficiency of health services, while better responding to the complex needs of patients with chronic conditions $[1,7]$.

Despite abundant evidence for the positive effects of IPC, studies have shown that the uptake of IPC in organizations remains weak; IPC is also inadequately practiced in healthcare teams $[8,9]$. Inadequate IPC has been associated with medication errors, patient safety problems, team conflict and patient mortality $[10,11]$. Thus, there is a great need for research identifying variables associated with IPC, particularly in mental health $(\mathrm{MH})$ primary care teams (PCTs) but also in $\mathrm{MH}$ specialized service teams

(c) The Author(s). 2020 Open Access This article is distributed under the terms of the Creative Commons Attribution 4.0 International License (http://creativecommons.org/licenses/by/4.0/), which permits unrestricted use, distribution, and reproduction in any medium, provided you give appropriate credit to the original author(s) and the source, provide a link to the Creative Commons license, and indicate if changes were made. The Creative Commons Public Domain Dedication waiver (http://creativecommons.org/publicdomain/zero/1.0/) applies to the data made available in this article, unless otherwise stated. 
(SSTs) [12, 13]. MH service reforms have been introduced $[14,15]$ with the aim of improving interdisciplinary teamwork [16-18]. Reforms have focused on improving interdisciplinary collaboration among professionals and team consolidation within MH-PCTs and MH-SSTs, but also on integrating primary and specialized care teams to provide better service for patients $[19,20]$. MH-PCTs using more limited expertise mainly treat patients with common mental disorders [21], making use of a restricted number of treatment sessions and brief interventions [22, 23]. This may include diagnosis and treatment of mild to moderate depression and anxiety, the provision of a range of shortterm biopsychosocial treatment interventions, and advice on referral options $[24,25]$. Conversely, MH-SSTs mostly treat patients with serious mental disorders or cooccurring mental disorders and substance use disorders, requiring specialist intervention with more intensive sessions and a longer time frame. Increasing evidence suggests the co-occurrence of substance use disorders and psychiatric illness such as schizophrenia and bipolar disorder, rendering treatment more difficult and resulting in greater use of diversified healthcare services [26]. In this context, the call for complex care involving multiple professionals from specialized services, and the need for professional collaboration is higher in SSTs than in primary healthcare [27, 28], where most previous research identifying variables related to IPC in MH has occurred $[8,13]$. The identification and comparison of variables associated with IPC among professionals working in MH-PCTs and MH-SSTs may provide a better understanding regarding the nature of collaboration among $\mathrm{MH}$ professionals in these different service settings in terms of maximizing IPC and making $\mathrm{MH}$ teams more successful.

To this end, a classification of variables that may influence IPC was constructed based on the Bronstein model [29], and on studies by San Martin-Rodriguez, Beaulieu, D'Amour, \& Ferrada-Videla [30] and Mulvale et al. [13] considering previous empirical research and data collection for this study. All variables recognized in the scientific literature in the health field as strongly associated with IPC were considered, and were categorized within this model. The model consisted of four conceptual blocks including individual, interactional, structural and professional role characteristics. Individual characteristics include demographic variables (e.g., gender, age) and personal attributes [14]; while interactional characteristics refer to those taking place among team members [30]. Structural or organizational characteristics include factors beyond the control of any individual team member; while professional role characteristics include selfidentity in individual professional practice [29].

Concerning individual characteristics, age, seniority on the team and belief in the benefits of interdisciplinary collaboration have been identified in prior studies as positively associated with IPC [31-33]. In addition, Pounder \& Coleman [34] found that women tend to work more collaboratively than men in teams.

Regarding interactional characteristics, previous research has identified knowledge sharing and knowledge integration as positively related to IPC [13, 30, 33, 35]. Knowledge sharing is defined as the act of providing or transferring knowledge to others [36]; while knowledge integration refers to the ability of team members to bring together knowledge from different disciplines to meet the needs of people with chronic and/or complex health conditions for which no single health professional has the requisite expertise [37]. Previous research also found that participation in decision-making, affective commitment toward the team, mutual trust and team climate were positively related to IPC $[13,14,35]$. Participation in decision-making refers to the discussions held among professionals working in a team that result in decisions around patient care based on consensus; while affective commitment toward the team is defined as the professional's psychological and emotional attachment to his/ her team [38]. Any worker given more responsibility and decision-making power over his/her job will produce higher quality work and achieve a higher level of job performance and satisfaction [13, 39, 40]. Previous research has also identified mutual trust and team climate as other interactional characteristics positively related to IPC [13, $30,33,35]$. Better team climate contributed to mutual respect and cohesion in teams [41]. By contrast, research identified employee conflict as negatively associated with IPC $[13,42]$. The confluence of several disciplines in managing complex or chronic cases, and diversity among individual professionals, tended to increase the potential for conflict in $\mathrm{MH}$ teams. Team conflict may hinder decisionmaking, team functioning and effectiveness while negatively impacting patient care and job performance [43]. Moreover, team autonomy, meaning work groups allowed sufficient organizational latitude to establish their own internal goals and work practices, is another interactional characteristic related to IPC that has produced mixed results, as reported in various studies: one finding positive associations between team autonomy and IPC [44], while another revealing that greater team autonomy may have adverse effects for IPC and team effectiveness [45]. Yet the benefits of team autonomy are clearly established in terms of a better exchange of skills, creativity, cohesion among team members and more effective group decision-making $[46,47]$, identifying team autonomy as a highly soughtafter quality in the MH domain.

Regarding structural characteristics that may influence IPC, positive relationships between organizational support and IPC have been identified in previous research $[3,33,48]$. Organizational support reflects employee perceptions of the extent to which an organization values 
its contribution and the degree of focus on organizational well-being; organizational support also includes logistical, administrative, and clinical supervision, and the development of training protocols or tools to assist employees in their work $[49,50]$. Results showed the highly positive impact of organizational support in terms of team performance [51] and reduced staff turnover [52]. Team size is another structural characteristics studied by many researchers in relation to IPC with mixed results $[3,13]$. One study found that members working in larger teams were less effective, less involved in decision-making processes and in IPC [3]; whereas another reported that small teams were highly dependent on the individual skills, abilities and experience of their members for meeting the biopsychosocial or multidimensional needs of patients [13].

Concerning professional role characteristics, type of profession, team identification and professional identification have been frequently studied in relation to IPC. While the cultures and values of particular healthcare professions create challenges for effective teamwork, reducing IPC effectiveness [53, 54], other healthcare professions transmit values, beliefs and behaviours that promote IPC [55]. Moreover, studies have demonstrated that team identification creates a sense of unity and solidarity among team members, improving IPC [56, 57]. By contrast, professional identification deriving from professional commitment and specific related practices was negatively related to IPC $[58,59]$. However, to the best of our knowledge, no studies have measured the impact of both team identification and professional identification, namely multifocal identification, on IPC. More concretely, multifocal identification refers to the fact that any team member identifies simultaneously with the team (team identification) and with his/her profession (professional identification) [60-62].

Many studies have tested variables for their influence on IPC. However, research has yet to compare variables associated with IPC among professionals working in MH-PCTs vs MH-SSTs. Based on the conceptual framework developed by Bronstein et al. [29], and further enhanced by the work of San Martín-Rodríguez et al. [29] and Mulvale et al. [13], this study thus aimed to identify variables associated with IPC, comparing MH-PCTs and MH-SSTs. As these two types of teams differ in terms of their activities, composition, client base, roles and functions, it was hypothesized that different variables related to MH-PCTs or MH-SSTs may influence IPC.

\section{Methods}

\section{Study design and sample}

This study emanated from a larger evaluation of local health service networks (LHSNs) implemented under the 2005-2015 MH care reform [63, 64] in Quebec (Canada).
As part of a global reform of the Quebec healthcare system [17], general hospitals, local community health centers, and nursing homes were merged to create 95 health and social service centers (HSSCs), mandated to oversee health service organization in their respective LHSNs, and to coordinate the various health service providers (e.g., psychiatric hospitals, community-based organizations, and medical clinics). The reform [17] required that at least one MH-PCT be established within each HSSC to treat patients with common mental disorders and provide followup services to stabilized service users with severe mental disorders. MH-PCT for the adult population integrated local teams such as biopsychosocial teams, and $\mathrm{MH}$ professionals (e.g. social workers, educators) based on roughly six psychosocial clinicians and 0.5 general practitioners per 100,000 inhabitants in the territory. MH-SST teams operated within hospital MH services (e.g. day hospital units, outpatient clinics, assertive community treatment).

The study included $\mathrm{MH}$ professionals from four Quebec LHSNs selected in consultation with an advisory committee composed of key decision makers in the Quebec MH care system [18]. Three LHSNs were served by a psychiatric hospital: two in the province's largest city and one in the capital. The fourth, located in a semi-urban area, relied on the services of a psychiatric department in a general hospital. Population areas ranged from 135,000 inhabitants in the semi-urban area to 300,000 served by the LHSN in the capital city.

To be eligible for the study, $\mathrm{MH}$ professionals had to work in one of the four selected LHSNs as members of a MH-PCT or MH-SST, and on teams composed of three or more $\mathrm{MH}$ professionals from at least two disciplines (e.g., psychologist, nurse, and social worker). A list of all $\mathrm{MH}$ professionals working in the teams that met these requirements was provided by the advisory committee. All potential study participants were contacted by email or telephone and invited to the study. A psychiatric research ethics board approved the multisite study protocol.

\section{Data collection and variables}

A total of $466 \mathrm{MH}$ professionals working in $\mathrm{MH}$ teams (154 in PCTs and 312 in SSTs) across the four LHSNs were invited to the study. Data collection involved the mailing of self-administered questionnaires to study participants, who completed and returned them between May 2013 and November 2014. To optimize the response rate, several recruitment strategies were conducted, including invitations by email and telephone, and information sessions held with MH professionals in PCTs and SSTs, and with their managers, who further assisted with recruitment. The questionnaire, which took approximately $45 \mathrm{~min}$ to complete, included sociodemographic information and questions related to diverse aspects of teamwork using standardized scales. Figure 1 presents the 
conceptual framework for the study based on the interdisciplinary collaborative framework described above. The framework describes the dependent variable and independent variables included in the study, considering previous empirical research and data collection for this study.

Table 1 describes the instruments used in the study to measure variables in the conceptual framework, including the Cronbach's alpha coefficients for each instrument from the original version (the English version for most), the validated French (or English) version and the study version used. The change in the Likert scales for some instruments used in the study should not reduce their reliability, validity or discriminating power $[65,66]$. IPC, the dependent variable, was measured using the Team Collaboration Questionnaire by Chiocchio, Grenier, O'Neill, Savaria and Willms [67], (Cronbach $\alpha$ coefficient between 0.91 and 0.92 ) based on a 7-point Likert scale $(1=$ completely disagree, $7=$ completely agree $)$. There were 14 items divided into four sub-dimensions: team communication (5 items), synchronization (3 items), explicit coordination (3 items) and implicit coordination (3 items). Independent variables were organized according to the four blocks of the conceptual framework: 1) Individual characteristics (4 variables) 2 ) Interactional characteristics (8 variables), 3) Structural characteristics (2 variables), and 4) Professional role characteristics (2 variables). All variables related to Interactional characteristics and one variable on Individual characteristics (belief in the benefits of interdisciplinary collaboration) were measured with validated instruments using 7-point Likert scales, while a single variable on Structural characteristics (organizational support), and another on Professional role characteristics (multifocal identification) also used instruments measured with 7point Likert scales. One of the Professional role characteristics variables, type of profession, was further categorized in terms of medical professions (e.g. specialist, general practitioner, nurse, pharmacist), psychosocial professions (e.g. social worker, psychologist), and general professions (e.g. technician, clerk).

\section{Analyses}

After scrutinizing the database, no outliers were found, and few missing values (less than $5 \%$ ), which were replaced by the means. Univariate, bivariate and multivariate analyses were performed for both IPC in primary care (MH-PCTs; $N=101)$ and IPC in specialized care (MH-SSTs; $N=214$ ). Univariate analyses included frequency distributions (numbers and percentages) for categorical variables, and central tendency measurements (means, standard deviations) for continuous variables. Linear regressions were conducted for bivariate analyses to assess associations between each independent variable and the dependent variable. For the bivariate analyses, the alpha value was set at 0.10 (which is less restrictive than 0.05), as some associations identified as not significant in the bivariate analysis, if considered with an alpha value at 0.05 , may become significant when tested against other variables in the multiple regressions. Variables significantly associated with each dependent variable in the bivariate analyses were then used to build the two multiple linear regression models (PCTs, SSTs) using the Backward elimination technique, with alpha set at 0.05 . The total variance explained (adjusted $R^{2}$ ) and goodness of fit ( $F$-test and $p$ value) were calculated for the two multiple regression models.

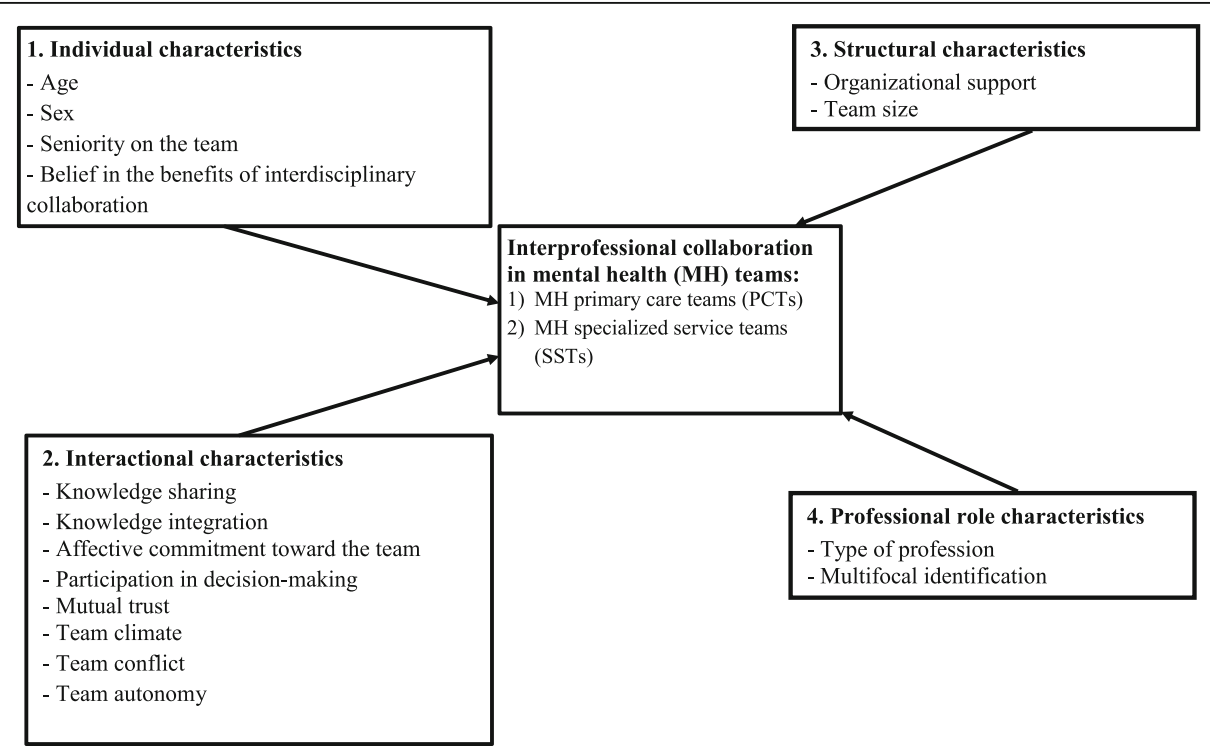

Fig. 1 Conceptual framework 
Table 1 Variables and instruments used in the study

\begin{tabular}{|c|c|c|c|}
\hline \multirow{2}{*}{\multicolumn{3}{|c|}{$\frac{\text { Blocks of variables } \quad \text { Variables }}{\text { 1) Independent variables (IV): }}$}} & \multirow[t]{2}{*}{ Instruments } \\
\hline & & & \\
\hline \multirow{4}{*}{$\begin{array}{l}\text { Individual } \\
\text { Characteristics }\end{array}$} & 1 & Age & Research team socio-demographic questionnaire. \\
\hline & 2 & Gender & Research team socio-demographic questionnaire. \\
\hline & 3 & $\begin{array}{l}\text { Belief in the benefits of } \\
\text { interdisciplinary collaboration }\end{array}$ & $\begin{array}{l}\text { Instrument designed by Sicotte et al. (2002) [1], composed of five items; } 5 \text { likert scale; } \\
\text { Cronbach alpha (a): } 0.92 \text {; (Original version in French). } \\
\text { Global internal consistency of the version for this study; } 7 \text { likert-scale; a: } 0.92 \text {. }\end{array}$ \\
\hline & 4 & Seniority in the team & Research team socio-demographic questionnaire. \\
\hline \multirow[t]{8}{*}{$\begin{array}{l}\text { Interactional } \\
\text { Characteristics }\end{array}$} & 5 & $\begin{array}{l}\text { Knowledge sharing (intention } \\
\text { to share knowledge) }\end{array}$ & $\begin{array}{l}\text { Instrument designed by Bock, Zmud, Kim and Lee (2005) [2], composed of five items;: } 5 \\
\text { likert scales; a: 0.93; (Original version). } \\
\text { Global internal consistency of the first French version: N.A. } \\
\text { Global internal consistency of the French version for this study; 7-likert scale: a:0.86. }\end{array}$ \\
\hline & 6 & Knowledge integration & $\begin{array}{l}\text { Instrument designed by Song and Xies (2000) [3], composed of nine items; } 11 \text { likert-scale; } \\
\text { a: N.A.; (Original version). } \\
\text { Global internal consistency of the first French Version: N.A. } \\
\text { Global internal consistency of the French version for this study; 7-likert scale; a:0.95. }\end{array}$ \\
\hline & 7 & $\begin{array}{l}\text { Affective commitment toward } \\
\text { the team }\end{array}$ & $\begin{array}{l}\text { Instrument designed by Allen and Meyer (1990) [4], composed of four items; } 7 \text { likert- } \\
\text { scale; a: 0.86-0.92; (Original version). } \\
\text { Global internal consistency of the first French Version: N.A. } \\
\text { Global internal consistency of the French version for this study; 7-likert scale; a:0.91. }\end{array}$ \\
\hline & 8 & $\begin{array}{l}\text { Participation in decision- } \\
\text { making }\end{array}$ & $\begin{array}{l}\text { Instrument designed by Campion, Medsker and Higgs (1993) [5], composed of three } \\
\text { items; } 5 \text { likert-scale; a: 0.88; (Original version). } \\
\text { Global internal consistency of the first French version [6]; a: 0.80. } \\
\text { Global internal consistency of the French version for this study; 7-likert scale; a:0.90. }\end{array}$ \\
\hline & 9 & Mutual trust & $\begin{array}{l}\text { Instrument designed by Simons and Peterson (2000) [7], composed of four items;5 likert- } \\
\text { scale; a: 0.89. (Original version). } \\
\text { Global internal consistency of the first French version [8];a:0.90. } \\
\text { Global internal consistency of the French version for this study; 7-likert scale; a:0.92. }\end{array}$ \\
\hline & 10 & Team climate & $\begin{array}{l}\text { Instrument designed by Anderson and West (1998) [9], composed of nineteen items ( } 4 \\
\text { dimensions); } 5 \text { likert-scale a: } 0.84-0.92 \text {; (Original version). } \\
\text { Global internal consistency of the First french version [10];: } 0.88-0.93 \text {. } \\
\text { Global internal consistency of the French version for this study; 7-likert scale; (sum of the } \\
4 \text { dimensions) a: } 0.84-0.93 \text {. }\end{array}$ \\
\hline & 11 & Team conflict & $\begin{array}{l}\text { Instrument designed by Jehn and Mannix (1991) [11], composed of nine-items ( } 3 \text { dimen- } \\
\text { sions); } 5 \text { likert-scale; a: } 0.93-0.94 \text {; (Original version). } \\
\text { Global internal consistency of the first French version [6]: a: } 0.75-0.93 \\
\text { Global internal consistency of the French version for this study; } 7 \text {-likert scale; (sum of the } \\
4 \text { dimensions) a: } 0.84-0.91 \text {. }\end{array}$ \\
\hline & 12 & Team autonomy & $\begin{array}{l}\text { Instrument designed by Campion, Medsker and Higgs (1993) [5], composed of three- } \\
\text { items; } 5 \text { likert-scale; a: 0.76; (Original version). } \\
\text { Global internal consistency of the first French version [6]: a: } 0.67 \\
\text { Global internal consistency of the French version for this study: 7-likert scale; a:0.81. }\end{array}$ \\
\hline \multirow[t]{2}{*}{$\begin{array}{l}\text { Structural } \\
\text { Characteristics }\end{array}$} & 13 & Organizational support & $\begin{array}{l}\text { Instrument designed by Spreitzer (1996) [12], composed of four-items. a: N.A.; (Original } \\
\text { version). } \\
\text { Global internal consistency of the first French version [13]; a::0.85 } \\
\text { French version for this study; 7-likert scale: a:0.84. }\end{array}$ \\
\hline & 14 & Team size & Research team socio-demographic questionnaire. \\
\hline \multirow{2}{*}{$\begin{array}{l}\text { Professional Role } \\
\text { Characteristics }\end{array}$} & 15 & Type of profession & Research team socio-demographic questionnaire. \\
\hline & 16 & Multifocal identification & $\begin{array}{l}\text { Instrument designed by Christ, Van Dick, Wagner, and Stellmacher (2003) [14], composed } \\
\text { of } 7 \text { items;: } 6 \text { likert-scale; Cronbach alpha (a): 0.79; (Original version) } \\
\text { Global internal consistency of the first French version [15]; a::0.69 } \\
\text { French version for this study; 7-likert-scale: a:N.A. }\end{array}$ \\
\hline $\begin{array}{l}\text { 2) Dependent } \\
\text { variable (DV): }\end{array}$ & & $\begin{array}{l}\text { Interprofessional collaboration } \\
\text { (IPC) }\end{array}$ & $\begin{array}{l}\text { Instrument designed by Chiocchio, Grenier, O'Neil, Savaria and Willms (2012) [16], } \\
\text { composed of a fourteen-items in four sub-dimensions: communication (5 items); } \\
\text { synchronization ( } 3 \text { items), explicit coordination ( } 3 \text { items); implicit coordination (3 items); } 7 \\
\text { likert-scale; a: } 0.91-0.92 ; \text { (Original version in French). } \\
\text { Global internal consistency of the version for this study a:0.94: }\end{array}$ \\
\hline
\end{tabular}




\section{Results}

Three hundred fifteen (315) MH professionals working in PCTs $(N=101)$ or SSTs $(N=214)$ participated in the study, for a $67.6 \%$ response rate. With regard to healthcare services, $32.1 \%$ of $\mathrm{MH}$ professionals worked in MH-PCTs and $67.9 \%$ in MH-SSTs. Most MH professionals were female: $70.2 \%$ in the total sample, $78.2 \%$ in MH-PCTs, and $65.4 \%$ in MH-SSTs. No significant differences were found between participants and non-participants with respect to distributions for team type [X2 $(1, N=466)=0.79 ; p=$ 0.68 ] and gender [X $2(1, \mathrm{~N}=466)=0.03 ; p=0.87]$. The mean age of study participants was 43 years for the total sample, 41.7 years in MH-PCTs, and 44.1 years in $\mathrm{MH}$ SSTs. Mean seniority on the teams was 3 years for the total sample, 2.25 years in MH-PCTs, and 3.44 in $\mathrm{MH}$ SSTs. Most participants in both the total sample and the two subsamples were psychosocial professionals $(77.2 \%$ in MH-PCTs vs. $44.4 \%$ in MH-SSTs); while the rest were medical professionals $(15.8 \%$ in MH-PCTs vs. $43.5 \%$ in MH-SSTs) or general professionals (7.9\% in MH-PCTs vs. $12.1 \%$ in MH-SSTs). IPC had a mean score of 8.022 (SD = 3.751) for PCTs, and 19.931 (SD = 3.747) for SSTs. Participant characteristics are presented in Table 2, along with significant variables from the bivariate analyses.

The multiple linear regression models are presented in Table 3. For MH-PCTs, four variables were independently and positively associated with IPC, including three related to Interactional characteristics (knowledge sharing, knowledge integration and team climate), and one related to Professional role characteristics (multifocal identification). This model explained $63.6 \%$ of total variance (adjusted $R^{2}$ ), and had acceptable goodness-of-fit. In the MH-SSTs, four variables were independently and positively associated with IPC, of which two related to Interactional characteristics (knowledge integration and team climate), one related to Structural characteristics (organizational support), and another related to Professional role characteristics (multifocal identification). The single variable related to Individual characteristics, age, was significantly and negatively associated with IPC. This model explained $55.0 \%$ of total variance (adjusted $\mathrm{R}^{2}$ ), and had acceptable goodness-of-fit.

\section{Discussion}

This study was to our knowledge the first to compare variables associated with IPC in MH-PCTs and MHSSTs. The findings revealed three variables independently and positively associated with IPC in both PCTs and SSTs (knowledge integration, team climate and multifocal identification); whereas knowledge sharing correlated with MH-PCTs only, and two other variables (organizational support and age) with MH-SSTs only. Therefore, in terms of variables significantly associated with ICP in MH-PCTs and MH-SSTs, there were as many differences as similarities, contrary to our hypothesis. This may be explained by the differences in teams working in primary care as compared with specialized care, described in the introduction, and by the fact that most PCTs were formed following the $\mathrm{MH}$ reform with staff from former SSTs. The increased promotion of integrated care among professionals from both PCTs and SSTs aimed at accommodating patients who need service at both levels of care may also explain our results. Moreover, while the proportion of medical professionals was greater among SSTs, and psychosocial professionals more prevalent among MH-PCTs, inter-professional collaboration (IPC) was not associated with type of professional in either MH-PCTs or MH-SSTs.

In addition, all four blocks in the conceptual framework were represented for MH-SSTs, whereas only two blocks represented MH-PCTs. No Individual or Structural characteristics variables were associated with IPC in MH-PCTs. This result may be explained by the recent nature of professional transfers to the new multidisciplinary MH-PCTs, and the early stage of team operations in terms of staff acquisition, the transfer of task-related knowledge, skill development as well as team support [68]. The embedding of IPC competencies (communication, synchronization, explicit coordination and implicit coordination), and interdisciplinary values and skills as well as team support into team structures would be expected to improve over time. It is only over a longperiod of time that IPC may become effective, resulting from practice-based training [69] and team building activities [70, 71] that would allow health professionals to break with old habits [70] by acquiring new knowledge, skills and attitudes [72]. By contrast, teamwork and other forms of collaboration were more the norm among psychiatrists and psychosocial professionals in specialized services, where cases are more complex and patient medical and social needs more recurrent.

Two variables related to Interactional characteristics (knowledge integration and team climate) were associated with IPC in both MH-PCTs and MH-SSTs. A high degree of knowledge integration and positive work environment are particularly important in managing most common $\mathrm{MH}$ problems, but also in treating severe and enduring $\mathrm{MH}$ problems such as schizophrenia and bipolar disorder. Studies have shown that IPC would be limited without knowledge integration from different disciplines and a positive working environment [30, 41]; while unsatisfactory or difficult conditions threaten the quality of patient care [53] and professional life [73, 74]. Knowledge integration and positive team climate may include better role clarification, inter-professional communication, and collaborative leadership, and this aligned with a patient-centred care approach based on a high level of IPC focused on the needs of patients and 
Table 2 Participant characteristics and unadjusted associations with interprofessional collaboration-IPC

\begin{tabular}{|c|c|c|c|c|c|c|c|c|c|}
\hline \multirow[b]{3}{*}{ Blocks } & \multirow[b]{3}{*}{ Variables } & \multicolumn{4}{|c|}{$\begin{array}{l}\text { MH Primary Care Teams (PCTs) } \\
(N=101)\end{array}$} & \multicolumn{4}{|c|}{$\begin{array}{l}\text { MH Specialized Service Teams } \\
\text { (SSTs) }(N=214)\end{array}$} \\
\hline & & \multicolumn{2}{|c|}{ Distribution } & \multicolumn{2}{|c|}{$\begin{array}{l}\text { Bivariate } \\
\text { analyses }\end{array}$} & \multicolumn{2}{|c|}{ Distribution } & \multicolumn{2}{|c|}{$\begin{array}{l}\text { Bivariate } \\
\text { analyses }\end{array}$} \\
\hline & & n/Mean & $\% / S D$ & Beta* $^{*}$ & $P$ & n/Mean & $\% / S D$ & Beta* $^{*}$ & $P$ \\
\hline Dependent variable & IPC (Mean/SD) & 8.02 & 3.75 & & & 19.93 & 3.75 & & \\
\hline \multirow[t]{6}{*}{ 1. Individual Characteristics } & Age (Mean/SD) & 41.71 & 10.56 & -.299 & .002 & 44.07 & 10.38 & -.125 & .069 \\
\hline & Gender (n/\%) & & & & & & & & \\
\hline & Female & 79 & 78.2 & & & 140 & 65.4 & & \\
\hline & Male & 22 & 21.8 & & & 74 & 34.6 & & \\
\hline & Seniority in the team (Mean/SD) & 2.25 & 3.07 & & & 3.44 & 5.56 & & \\
\hline & $\begin{array}{l}\text { Belief in the benefits of IPC score } \\
\text { (Mean/SD) }\end{array}$ & 5.99 & 0.82 & .445 & $<.001$ & 6.35 & .65 & .238 & $<.001$ \\
\hline \multirow[t]{8}{*}{ 2. Interactional Characteristics } & Knowledge sharing score ${ }^{a}$ (Mean/SD) & 5.51 & 0.97 & .556 & $<.001$ & 5.83 & .85 & .330 & $<.001$ \\
\hline & Knowledge integration score ${ }^{a}$ (Mean/SD) & 3.91 & 0.99 & .709 & $<.001$ & 4.41 & 1.16 & 609 & $<.001$ \\
\hline & $\begin{array}{l}\text { Affective commitment toward the team } \\
\text { score }^{a} \text { (Mean/SD) }\end{array}$ & 4.43 & 1.19 & .462 & $<.001$ & 5.06 & 1.20 & .470 & $<.001$ \\
\hline & $\begin{array}{l}\text { Participation in decision-making score }{ }^{a} \\
\text { (Mean/SD) }\end{array}$ & 4.44 & 1.45 & .455 & $<.001$ & 5.28 & 1.24 & .408 & $<.001$ \\
\hline & Mutual trust score & 5.13 & 1.05 & .204 & .004 & 5.23 & 1.21 & .519 & $<.001$ \\
\hline & Team climate score (Mean/SD) $^{\mathrm{b}}$ & 19.45 & 3.03 & .676 & $<.001$ & 20.92 & 3.48 & 686 & $<.001$ \\
\hline & Team conflict score (Mean/SD) & 3.39 & 1.79 & -.128 & .202 & 9.23 & 3.29 & -.356 & $<.001$ \\
\hline & Team autonomy score ${ }^{a}$ (Mean/SD) & 4.48 & 1.29 & .162 & .0106 & 5.12 & 1.12 & 0322 & $<.001$ \\
\hline \multirow[t]{2}{*}{ 3. Structural Characteristics } & Team size (Mean/SD) & 7.02 & 2.32 & & & 8.44 & 3.85 & & \\
\hline & Organizational Support score ${ }^{\mathrm{b}}$ (Mean/SD) & 4.61 & 1.23 & .342 & $<.001$ & 4.95 & 1.13 & .0449 & $<.001$ \\
\hline \multirow[t]{5}{*}{ 4. Professional Role Characteristics } & Type of profession (n/\%) & & & & & & & & \\
\hline & Medical professions & 16 & 15.8 & & & 93 & 43.5 & & \\
\hline & Psychosocial professions & 77 & 76.2 & & & 95 & 44.4 & & \\
\hline & General Professions & 8 & 7.9 & & & 26 & 12.1 & & \\
\hline & Multifocal identification score ${ }^{a}$ (Mean/SD) & 20.22 & 2.54 & .517 & $<.001$ & 20.97 & 2.61 & .461 & $<.001$ \\
\hline
\end{tabular}

${ }^{\mathrm{a}}$ Mean score (1 to 7 for each variable); $\min : 1$, max: 7 ; higher = positive ${ }^{\mathrm{b}}$ Mean score (1 to 7 for 4 dimensions); min: 4 , max: 28 ; lower = positive Beta*: Standardized coefficients Beta

their loved-ones for improving quality of care [53]. Knowledge integration in particular involves the development of a relational dynamic in which professionals influence each other in analyzing the situations encountered, and in articulating a shared vision and plan of action [53, 69, 74-76]. Knowledge integration coupled with positive and productive work environments may foster positive contacts among professionals in different disciplines that would enhance empathic responses while reducing anxiety levels among professionals [77].

The multifocal identification variable under Professional role characteristics was also associated with IPC in both MH-PCTs and MH-SSTs. This underlines the importance of professional identification for improving IPC in MH teams practicing from a multidisciplinary model of care, such as those responsible for expert assessments, case reviews and management of individuals with complex needs. Indeed, professional identification was experienced as a great source of satisfaction and motivation for workers whose professional skills were valued by other team members [78]. Moreover, strong team identity helped overcome multiple issues including those involving professional diversity or patient management $[79,80]$. Research has shown that successful teamwork was enhanced when team identification was sufficiently strong to moderate individual professional identifications [9]. In addition, numerous studies show that certain intergroup contacts may lead to harm and discrimination, which would require that a set of actions be taken to address power differentials [77].

The knowledge sharing variable under Interactional characteristics was associated with IPC in MH-PCTs only. This suggests the particular importance of knowledge sharing in the newly formed MH-PCTs dealing with 
Table 3 Variables independently associated with interprofessional collaboration (IPC): Multiple linear regressions

\begin{tabular}{|c|c|c|c|c|c|c|c|c|}
\hline \multirow[t]{2}{*}{ Linear regression models } & & \multirow{2}{*}{$\begin{array}{l}\text { Standardized } \\
\text { Coefficients } \\
\text { Beta }\end{array}$} & \multirow[t]{2}{*}{$\mathrm{t}$} & \multirow[t]{2}{*}{ Sig. } & \multicolumn{2}{|c|}{$\begin{array}{l}95.0 \% \text { Confidence Interval } \\
\text { for B }\end{array}$} & \multicolumn{2}{|l|}{$\begin{array}{l}\text { Collinearity } \\
\text { Statistics }\end{array}$} \\
\hline & & & & & LB & UB & Tolerance & VIF \\
\hline \multicolumn{9}{|l|}{ MH Primary Care Teams (PCTs) ${ }^{a}$} \\
\hline Total sample $(N=101)$ & (Constant) & & -1.584 & .116 & -7.259 & .814 & & \\
\hline \multirow[t]{3}{*}{ Interactional Characteristics } & Knowledge sharing score & .238 & 3.463 & .0001 & .395 & 1.457 & .767 & 1.303 \\
\hline & Knowledge integration score & .375 & 4.547 & $<.001$ & .796 & 2.030 & .536 & 1.866 \\
\hline & Team climate score & .265 & 3.119 & .002 & .119 & .537 & .504 & 1.984 \\
\hline Professional Role Characteristics & Multifocal identification score & .141 & 1.975 & .005 & -.001 & .419 & .710 & 1.408 \\
\hline \multicolumn{9}{|l|}{ MH Specialized Service Teams (SSTs) ${ }^{b}$} \\
\hline Total sample $(\mathrm{N}=214)$ & (Constant) & & 1.776 & .077 & -.341 & 6.536 & & \\
\hline Individual Characteristics & Age (Mean/SD) & -.114 & -2.450 & .015 & -.074 & -.008 & .973 & 1.028 \\
\hline \multirow[t]{4}{*}{ Interactional Characteristics } & Knowledge integration score & .240 & 3.819 & $<.001$ & .376 & 1.179 & .535 & 1.871 \\
\hline & Mutual trust score & .124 & 1.852 & .065 & -.025 & .795 & .469 & 2.131 \\
\hline & Team climate score & .323 & 3.828 & $<.001$ & .169 & .528 & .297 & 3.371 \\
\hline & Team autonomy score & .084 & 1.699 & .091 & -.042 & .567 & .868 & 1.152 \\
\hline Structural Characteristics & Organizational Support score & .106 & 1.931 & .005 & -.007 & .709 & .704 & 1.420 \\
\hline Professional Role Characteristics & Multifocal identification score & .094 & 1.689 & .005 & -.023 & .293 & .682 & 1.467 \\
\hline
\end{tabular}

MH Primary Care Teams ${ }^{\text {a }}$ : Adjusted R²: 0,636; Goodness of fit-F: $44.696 P<0.001$

MH Specialized Service Teams ${ }^{\mathrm{b}}$ : Adjusted $R^{2}: 0.550$; Goodness of fit-F: $38.159 P<0.001$

patients mainly affected by common mental disorders and substance use disorders as well as multiple biopsychosocial needs that require sharing of information, skills, and expertise [81, 82]. Consistent with our results, a number of studies demonstrated that collaboration rarely succeeds without knowledge sharing on teams [30, 83]. Knowledge sharing is also known to increase worker productivity and organizational performance [84, 85].

Organizational support, a Structural characteristics variable, was associated with IPC for MH-SSTs only. Organizational support entails multi-level leadership in overseeing the provision of team resources, adequate space for patient care, clear rules and procedures [2,30], a climate conducive to the development of good team working relationships [86], as well as leadership and administrative support [29]. This support is particularly essential in MHSSTs where a variety of professionals treat cases involving complex and recurring disorders (e.g. schizophrenia, bipolar disorders), and some agitated and/or aggressive patients $[87,88]$. Specialized care interventions also tend to occur in an emergency or crisis context, requiring a high level of organizational support. Organizational support has also had positive effects for reducing staff turnover [64] and on job performance [51].

Regarding Individual characteristics, our study identified a negative association between age and IPC, unlike some previous research (e.g. [31]), but only in MH-SSTs. This finding may have been due to the prevalence of younger professionals working in MH-SSTs, whose relative lack of work experience may have encouraged greater collaboration with others as compared with more experienced team members in order to minimize errors [89]. Another explanation may be that younger $\mathrm{MH}$ professionals are more open to innovation, and to knowledge acquisition, as in the adoption of best practices and IPC. Moreover, since around 2012 all Canadian programs for health professional have been accredited to provide interprofessional education related to their standards [90], which may prepare health science students to work in collaboration prior to their entry into professional practice. However, despite a growing body of research, little consensus exists concerning the effects of age on IPC, as younger professionals may also work with seniors who manage to enforce the status quo [31, 91].

Finally, some independent variables identified as significant in other studies were not related to IPC in this research, whether for MH-PCTs or MH-SSTs, which may be partly explained by the study context. However, some variables that were not in collinearity with others, but measured different dimensions, may have been relatively close in meaning (e.g. multifocal identification and belief in benefits of interdisciplinary collaboration). Most astonishing was that type of profession (in Professional role characteristics) was not related to IPC in our study. This result may have occurred because teams were too similar in terms of their mix of professionals to be differentially related to IPC, or perhaps due to the way in which each individual team was regrouped in terms of PCTs or SSTs. 


\section{Limitations}

Despite some important findings, this study had certain limitations. First, the study used a cross-sectional design, which did not permit the formulation of cause and effect inferences about the data. Second, the research did not include a control group, which would have allowed for comparisons. Third, MH-PCTs and MH-SSTs represented a diversified range of teams such as assertive community treatment teams, emergency department teams (SSTs), single access point or psychosocial teams (PCTs), that were not treated as specific team types in the analyses. Treating each team subtype separately may have produced different IPC associated variables. Studying specific teams with a complementary method such as case study analysis may also have brought additional information concerning team processes and dynamics to the results. In addition, there were more SST than PCT teams, and for some, such as emergency department teams, response rates were relatively low. Fourth, some variables identified as key variables in earlier ICP research (e.g. leadership, team power balance, and team culture) were not investigated in the present study [3, 28]. Fifth, since Likert-scales of the French instruments used in this study often differed from their original version, the mean scores may not be compared with those from previous studies. Sixth, IPC could have been measured with other validated instruments than the one used in this study (e.g. Assessment of Interprofessional Team Collaboration Scale [92]). Seventh, multivariate linear regression analyses cannot identify IPC moderators or mediators. A study using equation modelling analysis could be a further step for identifying such IPC data. Finally, the results may only be generalized to the Quebec MH system, and to the sites included in this study.

\section{Conclusion}

This study was innovative in a number of ways. First, it included a large sample of professionals working in $\mathrm{MH}$ PCTs or MH-SSTs located in four Quebec MH networks. Second, the study tested numerous variables previously identified as strongly related to IPC and organized within a conceptual framework. Moreover, it identified variables associated with IPC in both MH-PCTs and MH-SSTs, comparing IPC associated variables for the two practice settings. The two multivariate regression models identified three independent variables related to Interactional characteristics, and one each for Individual characteristics, Structural characteristics, and Professional role characteristics, respectively. Three independent variables were associated with both MH-PCTs and MH-SSTs, and three were specific to either MH-PCTs or MH-SSTs; as such, they reveal some variation in IPC across levels of care. This suggests the need for managers to promote the development and implementation of differentiated professional skills on teams, depending upon their required level of care provision. Surely, the maintenance of IPC depends upon the contributions of all team members; whereas their effectiveness may be directly influenced by managers themselves. Thus, at the level of specialized services, managers might focus their attention on organizational support without neglecting other variables identified in association with IPC in both MH-PCTs and MH-SSTs (i.e. knowledge integration, positive team climate and multifocal identification). At the primary $\mathrm{MH}$ level, managers should focus on the development of knowledgesharing competencies. Finally, more outreach activities and training of $\mathrm{MH}$ professionals are needed to promote interdisciplinary values and skills as well as interprofessional knowledge and IPC. All in all, MH professionals working as members of multidisciplinary teams need preparation and support to know how to work more effectively and collaboratively.

\section{Abbreviations}

HSSCs: Health and social service centers; IPC: Interprofessional collaboration; LHSNs: Local health service networks; MH: Mental health; MH-PCTs: Primary mental health care teams; MH-SSTs: Specialized mental health service teams; PCTs: Primary care teams; SSTs: Specialized service teams

\section{Acknowledgments}

We thank the individuals who participated in the research, including the advisory committee and network respondents, the research team and staff. We are especially grateful to Guy Grenier for his assistance in the preparation of this manuscript, and to Judith Sabetti for editorial assistance.

\section{Authors' contributions}

NNMKK and MJF designed analytical plan for the article. NNMKK wrote the article. JMB produced the quantitative analyses and tables. MJF and FC designed the overall research project, and MJF was responsible for the data collection. MJF, JMB and FC revised the final version of the article.

\section{Funding}

This study was funded by the Fonds de recherche du Quebec Santé (FRQS), grant number 22367 and the Prends Soin de toi Program.

\section{Availability of data and materials}

Signed confidentiality agreements prevent us from sharing the data. However, a copy of questionnaires may be obtained from the first author on request.

\section{Ethics approval and consent to participate}

The research ethics board of the Douglas Mental Health University Institute approved the multi-site study protocol (MP-IUMD-11037). Written informed consent was obtained from all participants at the beginning of the study.

\section{Consent for publication}

Not applicable.

\section{Competing interests}

The authors declare that they have no competing interests.

\section{Author details}

${ }^{1}$ Department of Management, Evaluation and Health Policy, Université de Montréal, School of Public Health, 7101 Parc Avenue, Montreal, Quebec H3N 1X9, Canada. ${ }^{2}$ Telfer School of Management, University of Ottawa, 55 Laurier Avenue East, Ottawa, Ontario K1N 6N5, Canada. ${ }^{3}$ Douglas Hospital Research Centre, Douglas Mental Health University Institute, 6875 LaSalle Boulevard, Montreal, Quebec H4H 1R3, Canada. ${ }^{4}$ Department of Psychiatry, McGill University; Douglas Hospital Research Centre, Douglas Mental Health University Institute, 6875 LaSalle Boulevard, Montreal, Quebec H4H 1R3, Canada. 
Received: 4 March 2019 Accepted: 30 December 2019

\section{Published online: 08 January 2020}

\section{References}

1. D'Amour D, Oandasan I. Interprofessionality as the field of interprofessional practice and interprofessional education: an emerging concept. J Interprof Care. 2005;19(Suppl 1):8-20.

2. Reeves S, Lewin S, Espin S, Zwarrenstein M. Interprofessional teamwork for health and social care. Chichester: Blackwell; 2010.

3. Xyrichis A, Lowton K. What fosters or prevents interprofessional teamworking in primary and community care? A literature review. Int J Nurs Stud. 2008;45:140-53.

4. Craven MA, Bland R, et al. Can J Psychiatry. 2006;51:7s-72s.

5. Byrnes V, O'Riordan A, Schroder C, Chapman CE, Medves J, Paterson M, Grigg R. South eastern interprofessional collaborative learning environment (SEIPCLE): nurturing collaborative practice. JRIPE. 2012;2:168-86.

6. Archer J, Bower P, Gilbody S, Lovell K, Richards D, Gask L, Dickens C, Coventry P. Collaborative care for depression and anxiety problems. Cochrane Database Syst Rev. 2012;10:CD006525.

7. Samuelson M, Tedeschi P, Aarendonk D, de la Cuesta C, Groenewegen P. Improving interprofessional collaboration in primary care: position paper of the European forum for primary care. Qual Prim Care. 2012;20:303-12.

8. Kates N, Mazowita G, Lemire F, Jayabarathan A, Bland R, Selby P, Isomura T, Craven M, Gervais M, Audet D. The evolution of collaborative mental health Care in Canada: a shared vision for the future. Can J Psychiatry. 2011;56:110.

9. Mitchell RJ, Parker V, Giles M. When do interprofessional teams succeed? Investigating the moderating roles of team and professional identity in interprofessional effectiveness. Hum Relat. 2011;64:1321-43.

10. Weinberg DB, Miner DC, Rivlin L. 'It depends': medical residents' perspectives on working with nurses. Am J Nurs. 2009;109:34-43 quiz 44.

11. Bender M, Connelly CD, Brown C. Interdisciplinary collaboration: the role of the clinical nurse leader. J Nurs Manag. 2013;21:165-74.

12. Bell AV, Michalec B, Arenson C. The (stalled) progress of interprofessional collaboration: the role of gender. J Interprof Care. 2014;28:98-102.

13. Mulvale G, Embrett M, Razavi SD. 'Gearing Up' to improve interprofessional collaboration in primary care: a systematic review and conceptual framework. BMC Fam Pract. 2016;17:83.

14. Smith GC. From consultation-liaison psychiatry to integrated care for multiple and complex needs. Aust N Z J Psychiatry. 2009;43:1-12.

15. WHO. The world Health Report 2008: Primary health care (now more than ever). Geneva: World Health Organization; 2008.

16. Nicaise $P$, Dubois $V$, Lorant $V$. Mental health care delivery system reform in Belgium: the challenge of achieving deinstitutionalisation whilst addressing fragmentation of care at the same time. Health Policy. 2014;115:120-7.

17. Ministère de la Santé et des Services sociaux. Plan d'action en santé mentale 2005-2010 - La force des liens. Québec: Ministère de la Santé et des Services sociaux; 2005.

18. Commonwealth of Australia. Fourth National Mental Health Plan: An agenda for collaborative government action in mental health 2009-2014. Barton, Australian Capital Territory; 2009.

19. Commonwealth of Australia. Fourth National Mental Health Plan- An agenda for collaborative government action in mental health 2009-2004: Commonwealth of Australia; 2009.

20. Fleury MJ. Primary mental healthcare reform in Quebec and the role and coordination strategies of general practitioners. Sante Ment Que. 2014;39:25-45

21. Thiebaut GC, Farand L, Fleury MJ. Policies and mental health action plans in OECD: lessons for Quebec? Sante Ment Que. 2014:39:65-84

22. Kisely S, Campbell LA. Taking consultation-liaison psychiatry into primary care. Int J Psychiatry Med. 2007;37:383-91.

23. Thielke $S$, Vannoy $S$, Unutzer J. Integrating mental health and primary care. Prim Care. 2007:34:571-92 vii.

24. Fleury MJ. Présentation. Santé mentale en première ligne. Sante Ment Que. 2009:34:19-34.

25. Fleury MJ, Farand L, Aube D, Imboua A. Management of mental health problems by general practitioners in Quebec. Can Fam Physician. 2012;58: e732-8 e725-731.

26. Wüsthoff LE, Waal H, Ruud T, Grâwe RW. A cross-sectional study of patients with and without substance use disorders in community mental health Centres. BMC Psychiatry. 2011;11:93.
27. Upshur C, Weinreb L. A survey of primary care provider attitudes and behaviors regarding treatment of adult depression: what changes after a collaborative care intervention? Prim Care Companion J Clin Psychiatry. 2008;10:182-6.

28. Korner M, Butof S, Muller C, Zimmermann L, Becker S, Bengel J. Interprofessional teamwork and team interventions in chronic care: a systematic review. J Interprof Care. 2016;30:15-28.

29. Bronstein LR. A model for interdisciplinary collaboration. Soc Work. 2003:48:297-306.

30. San Martin-Rodriguez L, Beaulieu MD, D'Amour D, Ferrada-Videla M. The determinants of successful collaboration: a review of theoretical and empirical studies. J Interprof Care. 2005;19(Suppl 1):132-47.

31. Sarma S, Devlin RA, Thind A, Chu MK. Canadian family physicians' decision to collaborate: age, period and cohort effects. Soc Sci Med. 2012;75:1811-9.

32. Rousseau C, Pontbriand A, Nadeau L, Johnson-Lafleur J. Perception of Interprofessional collaboration and co-location of specialists and primary care teams in youth mental health. J Can Acad Child Adolesc Psychiatry. 2017;26:198-204.

33. Bookey-Bassett S, Markle-Reid M, McKey CA, Akhtar-Danesh N. Understanding interprofessional collaboration in the context of chronic disease management for older adults living in communities: a concept analysis. J Adv Nurs. 2017;73:71-84.

34. Pounder JS, Coleman M. Women-better leaders than men? In general and educational management it still all depends. Leader Organ Dev J. 2002:23:122-33.

35. Caricati L, Guberti M, Borgognoni P, Prandi C, Spaggiari I, Vezzani E, lemmi $M$. The role of professional and team commitment in nurse-physician collaboration: a dual identity model perspective. J Interprof Care. 2015;29:464-8.

36. Bock GW, Zmud RW, Kim YG, Lee JN. Behavioral intention formation in knowledge sharing: examining the roles of extrinsic motivators, socialpsychological forces, and organizational climate. MIS Q. 2005;29:87-111.

37. Oandasan I, Reeves S. Key elements of interprofessional education. Part 2: factors, processes and outcomes. J Interprof Care. 2005;19 Suppl 1:39-48.

38. Pearce CL, Herbik PA. Citizenship behavior at the team level of analysis: the effects of team leadership, team commitment, perceived team support, and team size. J Soc Psychol. 2010;144:293-310.

39. Dunn S, Cragg B, Graham ID, Medves J, Gaboury I. Interprofessional shared decision making in the NICU: a survey of an interprofessional healthcare team. JRIPE. 2013:3:63-77.

40. Deluca DC, Valachich JS. Situational synchronicity or decision making. In: Adams F, Humphreys P, editors. Encyclopedia of decision making and decision support technologies. Volume 2. Hersey: Information Science Reference; 2008

41. Agreli HF, Peduzzi M, Bailey C. The relationship between team climate and interprofessional collaboration: preliminary results of a mixed methods study. J Interprof Care. 2017;31:184-6.

42. Bagshaw D, Lepp M, Zorn CR. International research collaboration: building teams and managing conflicts. Conflict Resol Q. 2007;24:433-46.

43. Brown J, Lewis L, Ellis K, Stewart M, Freeman TR, Kasperski MJ. Conflict on interprofessional primary health care teams--can it be resolved? J Interprof Care. 2011;25:4-10.

44. Langfred CW. Autonomy and performance in teams: the multilevel moderating effect of task interdependence. J Manag. 2005;31:513-29.

45. Lanaj K, Chang CH, Johnson RE. Regulatory focus and work-related outcomes: a review and meta-analysis. Psychol Bull. 2012;138:998-1034.

46. Parker SK, Williams HM. Effective teamworking: reducing the psychosocial risks. Norwich: HSE Books; 2001.

47. Hoegl M, Parboteeah KP. Autonomy and teamwork in innovative projects. Hum Resour Manag J. 2006;2006:67-79.

48. Pfaff KA, Baxter PE, Jack SM, Ploeg J. Exploring new graduate nurse confidence in interprofessional collaboration: a mixed methods study. Int J Nurs Stud. 2014;51:1142-52.

49. Eisenberger $R$, Hungtington $R$, Hutchinson S, Sowa D. Perceived organizational support. J Appl Psychol. 1986;1986:500-7.

50. Eisenberger R, Fasolo P, Davis-LaMastro V. Perceived organizational support and employee diligence, commitment, and innovation. J Appl Psychol. 1990;75:51-5.

51. Nadiri $\mathrm{H}$, Tanova C. An investigation of the role of justice in turnover intentions, job satisfaction, and organizational citizenship behavior in hospitality industry. Int J Hosp Manag. 2010;29:33-41. 
52. Tymon WGJ, Stumpf SA, Smith RR. Manager support predicts turnover of professionals in India. Career Dev Int. 2011;16:293-312.

53. Canadian Interprofessional Health Collaborative [CIHC]. A national interprofessional competency framework. Vancouver: Retired from: www.cihc. ca/files/CIHC_IPCompetencies_Feb1210.pdf; 2010.

54. Chiocchio F, Lebel P, Dube JN. Informational role self-efficacy: a validation in interprofessional collaboration contexts involving healthcare service and project teams. BMC Health Serv Res. 2016;16:153.

55. Bilodeau K, Dubois S, Pepin J. The contribution of nursing science to interprofessional knowledge development. Rech Soins Infirm. 2013;113:43-50

56. Kramer RM. Social capital and cooperative behavior in the workplace: a social identity perspective. Adv Group Process. 2006;23:1-30.

57. Van Dick R, Van Knippeberg D, Van Kerschreiter R, Hertel G, Wieseke J. Interactive effects of work group and organizational identification on job satisfaction and extra-role behaviou. J Vocat Behav. 2008:72:388-99.

58. Wackerhausen S. Collaboration, professional identity and reflection across boundaries. J Interprof Care. 2009:23:455-73.

59. McNeil KA, Mitchell RJ, Parker V. Interprofessional practice and professional identity threat. Health Sociol Rev. 2013;22:291-307.

60. Markon MP, Bamvita JM, Chiocchio F, Fleury MJ. Profiles of mental health care professionals based on work role performance. Psychiatry Q. 2017:88:827-38

61. Fleury MJ, Grenier G, Bamvita JM, Chiocchio F. Associated and mediating variables related to job satisfaction among professionals from mental health teams. Psychiatry Q. 2018;89:399-413.

62. Khalili H, Hall J, DeLuca S. Historical analysis of professionalism in western societies: implications for interprofessional education and collaborative practice. J Interprof Care. 2014;28:92-7.

63. Fleury MJ, Grenier G, Vallee C, Aube D, Farand L, Bamvita JM, Cyr G. Implementation of the Quebec mental health reform (2005-2015). BMC Health Serv Res. 2016;16:586.

64. Fleury MJ, Grenier G, Vallee C, Aube D, Farand L. Implementation of integrated service networks under the Quebec mental health reform: facilitators and barriers associated with different territorial profiles. Int J Integr Care. 2017;17:3.

65. Dawes J. Do data characteristics change according to the number of scale points used? An experiment using 5-point, 7-point and 10-point scales. Int J Market Res. 2008:50:61-77.

66. Preston CC, Colman AM. Optimal number of response categories in rating scales: reliability, validity, discriminating power, and respondent preferences. Acta Psychol (Amst). 2000;104:1-15.

67. Chiocchio F, Grenier S, O'Neill TA, Savaria K, Willms JD. The effects of collaboration on performance: a multilevel validation in project teams. IJPOM. 2012:4:1-37.

68. Kozlowski SWJ, Bell B. Work groups and teams in organizations. In: Weiner IB, Schmidt NW, Highouse S, editors. Handbook of Psychology Industrial and Organizational Psychology. Volume 12. London: Wiley; 2003. p. 333-75.

69. Salas E, Cooke NJ, Rosen MA. On teams, teamwork, and team performance: discoveries and developments. Hum Factors. 2008:50:540-7.

70. Salas E, Rosen MA. Building high reliability teams: progress and some reflections on teamwork training. BMJ Qual Saf. 2013;22:369-73.

71. Klein C, DiazGranados D, Salas E, Le H, Burke CS, Lyons R, Goddwin GF. Does team building work? Small Group Res. 2009:40:181-222.

72. Rosen MA, DiazGranados D, Dietz AS, Benishek LE, Thompson D, Pronovost PJ, Weaver SJ. Teamwork in healthcare: key discoveries enabling safer, highquality care. Am Psychol. 2018;73:433-50.

73. Shields M, Wilkins K. Enquête nationale sur le travail et la santé du personnel infirmier de 2005, résultats. Ottawa: Statistique Canada; 2006.

74. Choi K, Cho B. Competing hypotheses analyses of the association between group task conflict and group relationship conflict. J Organ Behav. 2011;30:963-82.

75. Howarth M, Warne T, Haigh C. "Let's stick together"--a grounded theory exploration of interprofessional working used to provide person centered chronic back pain services. J Interprof Care. 2012;26:491-6.

76. Adams TL, Orchard C, Houghton P, Ogrin R. The metamorphosis of a collaborative team: from creation to operation. J Interprof Care. 2014;28:339-44.

77. Pettigrew T, Tropp L. How does intergroup contact reduce prejudice? Metaanalytic tests of three mediators. Eur J Soc Psychol. 2008;38:922-38.

78. Feen-Calighan HR. Professional identify perceptions of dual-prepared art therapy graduates. Art Ther. 2012;29:150-7.
79. Van der Vegt G, Bunderson S. Learning and performance in multidisciplinaryteams: the importance of collective team identification. Acad Manage J. 2005;48:532-47.

80. Solansky TS. Team identification: a determining factor of performance. Manag Psychol. 2010;26:247-58.

81. Fleury MJ, Grenier G. Needs and appropriateness of help according to types of professionals and their users. IJPR. 2007;12:5-22.

82. Fleury MJ, Bamvita JM, Grenier G, Schmitz N, Piat M, Tremblay J. Adequacy of help received by individuals with severe mental disorders after a major healthcare reform in Quebec: predictors and changes at 5-year follow-up. Adm Policy Ment Health. 2016:43:799-812.

83. Lindh Falk A, Hopwood N, Abrandt Dahlgren M. Unfolding practices: a sociomaterial view of interprofessional collaboration in health care. Professions Professionalism. 2017;7:1-14.

84. Reychav I, Weisberg J. Good for workers, good for companies: how knowledge sharing benefits individual employees. Knowl Process Manag. 2009;16:186-97.

85. Kessel M, Kratzer J, Schultz C. Psychological safety, knowledge sharing, and creative performance in healthcare teams. Creat Innov Manag. 2012;21:147-57.

86. Baxter P, Markle-Reid M. An interprofessional team approach to fall prevention for older home care clients 'at risk' of falling: health care providers share their experiences. Int J Integr Care. 2009:9:e15.

87. Wholey DR, Zhu X, Knoke D, Shah P, Zellmer-Bruhn M, Witheridge TF. The teamwork in assertive community treatment (TACT) scale: development and validation. Psychiatr Serv. 2012;63:1108-17.

88. Van Rijswijk E, Van Hout H, Van de Lisdonk E, Zitman F, Van Weel C. Barriers in recognising, diagnosing and managing depressive and anxiety disorders as experienced by family physicians; a focus group study. BMC Fam Pract. 2009;10:52.

89. Courtenay M, Nancarrow S, Dawson D. Interprofessional teamwork in the trauma setting: a scoping review. Hum Resour Health. 2013;11:57.

90. Accredition of Interprofessional healtth Education (AIPHE): Principels and practices for integrating interprofessional education into the accreditation standards for six health professions in Canada. https://casn.ca/wp-content/ uploads/2014/12/AIPHEPrinciplesandPracticesGuidev2EN.pdf.

91. Hansson A, Arvemo T, Marklund B, Gedda B, Mattsson B. Working together-primary care doctors' and nurses' attitudes to collaboration. Scand J Public Health. 2010;38:78-85.

92. Orchard C, Pederson LL, Read E, Mahler C, Laschinger H. Assessment of Interprofessional team collaboration scale (AITCS): further testing and instrument revision. J Contin Educ Health Prof. 2018;38:11-8.

\section{Publisher's Note}

Springer Nature remains neutral with regard to jurisdictional claims in published maps and institutional affiliations.

Ready to submit your research? Choose BMC and benefit from:

- fast, convenient online submission

- thorough peer review by experienced researchers in your field

- rapid publication on acceptance

- support for research data, including large and complex data types

- gold Open Access which fosters wider collaboration and increased citations

- maximum visibility for your research: over $100 \mathrm{M}$ website views per year

At $\mathrm{BMC}$, research is always in progress.

Learn more biomedcentral.com/submission 